\title{
A TIRANIA DA MODA SOBRE O CORPO: SUBMISSÃO VERSUS SUBVERSÃO FEMININA
}

\author{
Fashion Tyranny over the Body: Female Submission Versus \\ Subversion
}

\author{
La Tiranía de la Moda en el Cuerpo: La Sumisión Frente a la \\ Subversión Femenina
}

\author{
La Tyrannie de la Mode sur le Corps: La Soumission Verus la \\ Subversion Féminine
}

\begin{abstract}
Resumo
Este artigo propõe uma discussão sobre o padrão estético na atualidade, construindo um paralelo com o curso histórico da apropriação do corpo e os múltiplos significados de beleza. As implicações de estar dentro ou fora deste padrão contemporâneo imposto pela mídia serão aspectos abordados, visando entender as possíveis relações existentes entre a moda e a busca por essa beleza massificada, idealizada e paradoxalmente identitária. Estereótipos femininos que adquiriram fama em virtude do padrão corporal foram analisados; mulheresfruta, cujo perfil curvilínio e farto está ligado à sensualidade contrastam com aquele das passarelas, onde a escassez de forma e de alimento associa-se a androginia, ao sofrimento e à contestação. Resquícios do patriarcado estão presentes na força coercitiva de normas e regras atribuídas aos gêneros, designando papéis e espaços de ocupação. As razões pelas quais a magreza se faz presente no imaginário feminino também serão objeto de estudo, tomando como base teórica os estudos queer e de gênero.
\end{abstract}

Palavras-chave: moda; corpo; gênero; mídia; magreza.

\begin{abstract}
This paper proposes a discussion about the aesthetic standard established nowadays, presenting a parallel between the historic course of body appropriation and the multiple beauty senses. The implications of being inside or outside this contemporary standard imposed by the media will be approached, in an effort to understand the possible relations existents between fashion and the search for this massified beauty, idealized and paradoxically identifying. Female stereotypes that acquired fame by their body standard were analyzed, "mulheres-fruta", whose curvilinear and huge shape is linked to sensuality opposes to the ones from the catwalks, in which the lack of shape and food are associated to androgyny, to suffering and contestation. Remains of the patriarchy can be seen in the coercive strength of the standards and rules attributed to the different genders, designating social rules and places in society. Using the gender studies and queer studies the paper will analyze the reasons why the thinness is among the female's imaginary.
\end{abstract}

Keywords: fashion; body; gender; media; thinness.

\section{Resumen}

Este articulo propone una discusión sobre el patrón estético en nuestra actualidad, construyendo un paralelo con el curso histórico de la tomada del cuerpo y sus múltiplos significados de belleza. Las implicaciones de estar dentro o afuera de este patrón contemporáneo impuesto por la media serán algunos aspectos abordados, objetivando entender las posibles relaciones existentes en la moda y la busca por la belleza masificada, idealizada y paradoxalmente formadora de su propia identidad. Fueron analizados estereotipos femeninos que adquieren fama en virtud del patrón corporal, mujeres con
Artigo Original

Fernanda Lyrio Heinzelmann ${ }^{(1)}$ Patrícia Fasolo Romani ${ }^{(2)}$ Adriana da Silva Lessa ${ }^{(3)}$ Marília Saldanha da Silva ${ }^{(4)}$ Marlene Neves Strey ${ }^{(5)}$

1) Mestra em Psicologia Social (PUCRS).

2) Doutora em Psicologia (PUCRS) e professora do Curso de Psicologia da FADERGS

3) Psicóloga (PUCRS) e pósgraduanda em Terapia Sistêmica (CEFIPOA).

4) Mestra em Psicologia (PUCRJ).

5) Professora Doutora do Curso de Psicologia da PUCRS (Graduação e Pósgraduação). Coordenadora do grupo de pesquisa Relações de Gênero.

Recebido em: 05/09/2013

Revisado em: 19/06/2014

Aceito em: 09/11/2014 
cuerpo curvilíneo y voluptuoso esta asociado a la sensualidad en contraste con aquella de las pasarelas, donde la escasez de forma y de alimento se asocia a la androginia, al sufrimiento y la contestación. Resquicios del patriarcado se hacen presente en la fuerza coercitiva de las normas y reglas atribuidas a los géneros, designando papeles e espacios de ocupación. Las razones por las cuales la delgadez se hace presente en el imaginario femenino también serán objeto de estudio, teniendo como base teórica de los estudios queer y de genero.

Palabras clave: moda; cuerpo; género; medios de comunicación; delgadez.

\section{Résumé}

CCet article présente une analyse de la norme esthétique d'aujourd'hui, en considerant la construction d'un parallèle avec le cours historique de la propriété du corps féminin et les multiples significations de la beauté. Les implications d'être dans ou hors de cette tendance contemporaine imposée par les médias ont été abordés certains aspects, afin de comprendre la relation possible entre la mode et la recherche de la beauté en caractère massif, idéalisée et avec une identité encore paradoxale. Les stéréotypes qui ont acquis la célébrité en raison de la configuration du corps ont été analysés; "femmes-fruits" brésiliennes, dont le profil du corps tout en courbes et de remplissage est relié à la sensualité contraste avec celui (le corps de modèles) des allées, où la pénurie de la forme et de la nourriture est associée à l'androgynie, à la souffrance et à la protestation. Les traces du patriarcat sont présentes dans la force coercitive des normes et desrègles dans les genres, en déterminant l'attribution des rôles et des zones d'occupation. Les raisons pour lesquelles la minceur est présente dans l'imagerie féminine ont été également étudiées, en prenant comme base les études théoriques "queer" et de genre.

Mots-clés: mode; corps; genre; médias; minceur.

A preocupação estética tem se mostrado cada vez mais expressiva, onde a singularidade está perdendo espaço para uma massificação de comportamentos, porém não é de hoje que tal hábito enraizou-se nas sociedades. A Bíblia já datava a prática da maquiagem, assim como o Oriente Antigo nos fala de beleza, com suas paletas de cores e seus delineadores para olhos expostos em museus como Louvre e British Museum. A preocupação com a imagem corporal sempre se fez presente, independentemente da época ou classe social (Rousso, 2000).

Desde os primórdios do século XX, a adequação do corpo como atributo de beleza e inclusão social é perseguida pelas mulheres, condição que as destacava juntamente com os papéis de esposa, cuidadora do lar e mãe. Atualmente, a mulher ocupa espaços e posições de destaque fora do âmbito doméstico, mas a aparência continua sendo alvo de preocupação e pertencimento sócio-cultural; essa questão tem impacto dentro e fora do mundo da moda, gerando um motocontínuo em nível de consumo, que movimenta milhões e define identidades (Martins, 2010; Severiano, Rêgo \& Montefusco, 2010; Vilhena \& Novaes, 2008).

Em novembro de 2009, em entrevista ao jornal online especializado em moda, Women's Wear Daily (Costello, 2009), a modelo britânica Kate Moss declarou que um de seus lemas na vida é "nada é melhor do que se sentir magra". Esta declaração, que gerou revolta de parte do público e da imprensa, ilustra com clareza o perfil estético proposto e propagado pela indústria da moda desde o século passado, a partir das palavras de uma profissional veterana nesse mercado. Apesar de controversa, a percepção de Moss sobre a vida tem fundamento, já que o próprio mercado de moda atribui à modelo a popularização do corpo magro e do waif-look a partir da década de 90; este termo em inglês se refere a uma criança órfã, abandonada, negligenciada, desprovida de alimentação, aparência típica das modelos preferidas nas passarelas. Del Priore (2000) menciona a magreza ativa como resposta à gordura passiva da Belle Èpoque, onde o sobrepeso e a obesidade eram sinônimos de fartura econômica.

A magreza excessiva presente nas imagens relacionadas à moda tornou-se um tema muito abordado na última década. Muitas vezes o assunto vem à tona em situações extremas, como o caso da modelo brasileira Ana Carolina Macan, falecida em 2006, aos 21 anos, em decorrência da anorexia nervosa. A notícia do trágico falecimento da modelo abriu espaço na mídia nacional para o debate sobre o peso e saúde das modelos, resultando em medidas preventivas tomadas pela indústria de moda local. $\mathrm{Na}$ temporada de moda brasileira seguinte, em janeiro de 2007, a São Paulo Fashion Week (SPFW), evento bi anual de moda que apresenta coleções das grifes nacionais na forma de desfiles, estabeleceu normas, junto ao Ministério Público de São Paulo, "para preservar a integridade das modelos presentes no evento e ter garantias de que elas estão aptas a exercer a profissão" (Fashion Forward, 2010). As medidas, em vigor até hoje, incluem idade mínima de 16 anos para contratação e a exigência de atestado médico garantindo a plena saúde e condições de trabalho das profissionais. Vale lembrar que são medidas que desde então regulam apenas a participação das mulheres nas passarelas, sugerindo residir no gênero o problema. As mulheres constituem maior número na passarela do evento, uma vez que 26 marcas são voltadas para o público feminino e apenas cinco, para o masculino.

Além disso, também em 2007, a SPFW lançou uma campanha com cartilhas de conscientização impressas e online distribuídas às modelos, suas mães e pais e aos seus agentes para "promover a alimentação saudável". $\mathrm{O}$ material, que pode ser obtido no website do evento 
(São Paulo Fashion Week, 2007), reúne recomendações e orientações sobre alimentação, dieta e manutenção do peso assinadas por uma nutricionista e uma médica psiquiatra. As informações presentes na cartilha de forma alguma ajudam a desmistificar a ideia de saúde associada exclusivamente ao corpo magro. Pelo contrário, apontam cuidados necessários com a alimentação a fim de perder peso ou mantê-lo. No final da cartilha encontra-se uma breve explicação sobre transtornos alimentares e seus sintomas e estão indicados endereços de instituições que tratam dos doentes. Em nenhum momento questionou-se o motivo do perfil estabelecido. As atitudes tomadas em âmbito nacional pela indústria de moda reforçam a noção de que o corpo magro é o ideal e que as precauções a serem tomadas surgem na intenção de mantê-lo dessa forma e não no intuito de repensar a hegemonia da magreza.

Visando compreender as intersecções entre moda e padrões de beleza, abordaremos o corpo da forma como é percebido fora do universo da moda, aquele que pode ser visto não na passarela, mas nas ruas do Brasil e que representa a maioria das mulheres brasileiras. Sendo assim, o objetivo deste artigo é justamente aprofundar as relações sociais e de gênero que acreditamos ter relação íntima na busca atual pela magreza.

\section{Corpos das Ruas}

Ainda que a magreza possa ser entendida como uma premissa no mercado de moda, sua reprodução é nítida em outros contextos. Estudos conduzidos pela antropóloga Mirian Goldenberg (2002) e pela psicóloga Lucia Stenzel (2004), demonstram que adolescentes e mulheres que não estão envolvidas profissionalmente com a moda também desejam ter um corpo magro. Stenzel (2004, p.186) entrevistou adolescentes brasileiras e, a partir de seus depoimentos, constatou que elas estão em busca de "um corpo artificial desprovido de excessos de gordura; um corpo que poderia ser chamado de um corpo light." O entendimento do que é um corpo light, de acordo com a autora, seria expresso no simples ato de vestir uma calça de tamanho pequeno. Light é um termo usado pela indústria alimentícia para designar alimentos pouco calóricos. A existência dessa palavra na fala das entrevistadas demonstra o quanto o discurso que estimula as dietas e controle da alimentação (presente nas cartilhas da SPFW) está instituído no cotidiano adolescente.

A ideia de corpo enxuto também aparece entre as mulheres mais velhas. Goldenberg (2005) percebeu que o corpo desejado pelas mulheres do Rio de Janeiro difere do que os homens cariocas entendem como bonito para o sexo oposto. A pesquisadora uniu os dados obtidos através desse estudo a uma matéria publicada pela revista Época, que apontou o mesmo fato: elas querem emagrecer para seduzir, mas eles afirmam não gostar de mulher magra. Os resultados da pesquisa demonstram ainda que a preocupação feminina com o corpo é tão grande que acaba por interferir na vida sexual das entrevistadas. Muitas se disseram inseguras quanto ao próprio corpo, evitando exibi-lo ao parceiro.

Retomando o lugar do corpo na história, delimitamos o século XX como palco de diversos avanços no conhecimento e na sua apropriação pelas ciências. Neste mesmo período, a Psicanálise introduziu o pensamento do corpo afetado pelo inconsciente na forma de manifestações psicossomáticas. A questão da imagem corporal também foi objeto de estudo, onde uma ordem cultural livre de repressões sociais foi pensada. Não se trata somente da busca desenfreada de um corpo "sarado", magro ou qualquer padrão pretendido, mas também a busca de uma mente isenta de sofrimento (Queiroz, 2008).

Apesar dos anseios em relação ao próprio corpo, as brasileiras não estão mais magras (Gaier \& Grudgings, 2010). Dados do IBGE (2008-2009) apontam um aumento na quantidade de obesos no Brasil, o que deixa a dúvida sobre a aplicação prática do discurso da magreza no cotidiano das pessoas. Stenzel (2004) sugere que a existência dessas realidades opostas relaciona-se à interdependência entre ambas, pois uma depende da outra para existir e persistir. A valorização da magreza não seria possível sem a desvalorização do corpo obeso e possivelmente o aumento gradual de casos de obesidade acabe por incentivar o desejo de uma magreza ainda mais extremada.

Tanto no imaginário nacional como no internacional estão presentes as formas do corpo da mulher brasileira, com destaque para as nádegas e quadris. Curiosamente, uma das brasileiras de maior projeção no mundo nas duas últimas décadas, a modelo Gisele Bündchen não se encaixa nessa descrição. O sucesso de Gisele tem popularizado uma noção de beleza nacional diferente no exterior, contudo ela não necessariamente representa a mulher que vemos nas ruas do país. Gisele, como outras brasileiras que fizeram carreira na moda internacional, vem de uma cidade do interior do sul do país, onde as imigrações alemã e italiana foram marcos na constituição da população local. Ainda que não seja possível afirmar que exista uma única forma de beleza nacional que represente a mulher brasileira, é preciso atentar ao fato de que, num país marcado pela miscigenação, a beleza branca europeia, da qual ela é representante, é a utilizada para vender bens de consumo de toda espécie. A partir de 2009 foi estipulado que no mínimo 10\% do casting dos desfiles da SPFW seja composto por modelos negras ou indígenas, o que em termos matemáticos se reverte em representação inexpressiva, já que, num desfile composto por dez modelos, apenas uma precisaria não ser branca. $\mathrm{O}$ debate nesse sentido é frequente, pois organizadores e 
estilistas alegam que a diversidade cultural brasileira não se manifesta no catálogo das agências de modelos e que faltam profissionais negras e indígenas no mercado. A constatação não é nenhuma surpresa se for levado em consideração o investimento financeiro contínuo associado a essa profissão. Além dos gastos com a manutenção da aparência, uma modelo que deseja manter-se no mercado precisa ter um portifólio atualizado, com fotos que na maioria das vezes são pagas por ela própria (Farias, 2009); assim sendo, quem pode investir mais, aparecerá mais.

Talvez a mulher branca e magra represente a realidade de poucos num país de muitos, em que essa não é a única construção estética válida e entendida como bela. Outra leitura do corpo nacional envolve o ideal "sarado", associado à malhação intensa. Nos últimos anos a popularização da música e da cultura funk, associada às camadas menos favorecidas economicamente, disseminou na mídia o visual da mulher malhada, com músculos tonificados e bem bronzeada (Borowski, 2008). As academias de ginástica estão presentes por todo o Rio de Janeiro, inclusive nas favelas, popularizando a cultura do corpo malhado (Malysse, 2002). As "mulheres-fruta", também conhecidas como "popozudas", claramente se diferenciam das mulheres da moda: elas são mais baixas, têm pele mais escura, seios, coxas, quadris e bumbum maiores. Mas vale lembrar que mesmo no universo da "popozuda" vende-se um ideal de saúde associado a um corpo trabalhado com muito empenho e principalmente, livre de gordura. No elitismo da moda ou na popularidade do funk, a opressão feminina fica implícita no discurso do corpo "saudável". Seja a mulher "sarada" ou magra, a exigência de um corpo a serviço da beleza é a mesma.

\section{Corpos Famintos}

A cultura da fome feminina não é recente e está associada a uma ideia de corporalidade frágil e delicada que se alimenta de porções mínimas. Na época vitoriana, até mesmo as roupas dificultavam a ingestão de alimentos, já que peças como o espartilho apertavam todo o tórax feminino (Strey, 2004). Mesmo as atividades socialmente desempenhadas pelas mulheres, que compõem o imaginário de feminilidade ocidental, não estão associadas ao uso da força física, sugerindo também uma alimentação diferenciada.

No contexto atual, privar o corpo de alimentos significa ter controle sobre uma das necessidades mais básicas do ser humano: a fome. É a serviço do corpo faminto que surgem transtornos alimentares como a anorexia. As regras rígidas que regulam tanto o que é ingerido quanto o que é eliminado são algumas das premissas no cotidiano anoréxico, cuja meta máxima - a magreza idealizada - implica em privações autoimpostas (Halfen \& Damasceno, 2010; Vieira, 2008). A anorexia expressa uma tentativa de meninas e mulheres, acometidas por essa enfermidade, em se afirmarem como sujeitos dotados de valor e especialmente de poder. A moda torna-se um fator de grande influência nesse momento, pois ela é, como disse Kathia Castilho (2004), uma maneira dos sujeitos construírem modos de ser e estar no mundo, numa linguagem que se manifesta também no corpo. Logo, limar os excessos de gordura passa a ser fundamental. Não se trata apenas de se encaixar no padrão magro, mas de demonstrar que o corpo expressa a linguagem desta moda e que é resultado de muita dedicação e sacrifícios (Bordo, 1997).

A inanição voluntária expressa ainda um chamado por atenção e que poucas vezes ganha o reconhecimento devido. Em protestos políticos, por exemplo, não é raro ver pessoas apelando para a greve de fome, submetendo-se a um sacrifício e subvertendo o sistema vigente. Assim sendo, não seria a magreza excessiva um protesto inconsciente quanto à posição feminina na sociedade e seus ditames? Afinal, a manifestação contrária ao que está instaurado denota uma rebeldia frente ao poder dominante, onde o status quo é contestado e refutado através de uma atitude aparentemente passiva e martirizada.

A filósofa Susan Bordo (1997) descreve os transtornos alimentares no século XX como a versão atual das patologias historicamente associadas ao universo feminino, como eram a histeria e a neurastenia no século XIX. No entendimento de Bordo (2003), os transtornos alimentares deveriam ser classificados como patologias sociais e não psicológicas, como são normalmente tratadas. Todavia reconhecer a existência das duas patologias, a social e a psicológica, sem dicotomiza-las, é fundamental para a compreensão global e aprofundada do problema. Lembremos que o indivíduo é atravessado pelo social e contextualizá-lo ao longo da sua trajetória quer dizer incluí-lo numa história particular com interferências ambientais diversas.

A autora supracitada afirma também que reduzir gradativamente o espaço que o corpo ocupa tem significado simbólico e político dentro das normas variáveis que governam a construção histórica do gênero, ainda que esse movimento contrário seja próprio de uma minoria. Apesar da dimensão dada ao corpo, a anorética denuncia e renuncia a alguns estereótipos de feminilidade: a maternidade (santa) e a sedução (pecadora).

O corpo na maternidade é outro assunto que na moda e na mídia é pautado por um discurso confuso e ambivalente. Se por um lado, a mulher está culturalmente associada predominantemente à imagem de mãe, por outro, existe todo um aparato informando que a gravidez precisa ser vivida "com moderação", sem descuidar da aparência do corpo. 
Essa condição muitas vezes vem travestida de cuidados com a própria saúde e especialmente com a saúde do bebê. Maria Simone Schwengber (2009) estudou os cuidados estéticos propostos pela mídia para as mulheres grávidas e conta que no desejo de eliminar marcas da gravidez há inclusive quem negocie com o parceiro cirurgias plásticas e lipoaspirações a serem realizadas quando a criança completar um ano; uma espécie de moeda de troca por gestar o bebê e com isso sofrer mudanças no corpo. Essa cobrança pelo corpo esbelto, mesmo nessa circunstância, está também relacionada ao culto à juventude. $\mathrm{O}$ mito da juventude tem relação direta com o discurso da magreza, refletindo o ideal a ser alcançado, no qual a idade é inversamente proporcional ao desejo proeminente. Uma mulher com o corpo já formado tem curvas, coxas mais grossas, volume nos quadris, seios. Mas a premissa da juventude eterna sugere que as mulheres se pareçam com pré-adolescentes, nas quais essas mudanças ainda não aconteceram.

Um dado importante sobre a fome enquanto ideologia, conceito criado por Susan Bordo, refere-se à manifestação da maioria dos casos de anorexia a partir da puberdade, justamente quando o corpo começa a se modificar (Halfen \& Damasceno, 2010). É também nessa época de transição que tem início a carreira de muitas modelos. Meninas que sonham com essa carreira desde cedo já convivem com as cobranças estéticas e o controle do próprio apetite, através das mais diversas dietas e recursos alternativos. Publicações voltadas para o público adolescente, como a Revista Capricho, são um exemplo claro disso, ao propagar em suas páginas discursos sobre cuidados com o corpo que com o tempo só serão aprimorados (Niemeyer \& Kruse, 2008).

Da mesma maneira que nas cartilhas da São Paulo Fashion Week, as informações sobre saúde e transtornos alimentares são contraditórias, nas revistas como a Capricho, o tratamento dado para esse assunto é semelhante. Fernanda Niemeyer e Maria Henriquieta Kruse (2008) analisaram o discurso da publicação como estimulador do padrão magro, informando sobre o problema sério que constituem os transtornos alimentares, mas ao mesmo tempo ensinando modos de viver que reforçam toda a base cultural que incentiva a existência de tais patologias. Se, por um lado, a revista aponta estar sempre de dieta e "fazer tudo a pé" como possíveis sintomas de problemas de saúde, por outro ensina que fazer exercícios é importante para manter a forma e que determinados alimentos engordam e devem ser evitados. Dessa forma, percebe-se que desde cedo as mulheres são bombardeadas por informações sobre como cuidar do próprio corpo a partir de regras que estipulam o que é ou não saudável.

A busca incessante pela juventude tornou-se uma das justificativas para a magreza. Ainda que hoje existam regras para a contratação de meninas menores de idade como modelos, é preciso lembrar que elas valem para um evento específico, e se resumem aos desfiles. Nas páginas de revistas, catálogos e demais trabalhos desempenhados por essas profissionais, não é raro ver meninas muito jovens trabalhando. E, se na década de 90 as chamadas "new faces" - "novo rosto"-, iniciavam carreira em matérias de revistas dirigidas às adolescentes, no século XXI elas estão por toda parte.

Na temporada Primavera-Verão 2010 a grife italiana Miu Miu contratou Lindsey Wixson, modelo britânica de apenas 15 anos, alegando que ela era o protótipo do espírito livre no ápice da feminilidade (Odell, 2010). É pouco provável que o público da marca, composto por mulheres mais velhas, com poder aquisitivo para consumila, se identifique com uma adolescente. Mas para essa grife, uma menina de 15 anos é a expressão da feminilidade que desejam passar. No entanto, a escolha de uma menina como representação de mulher não é exclusividade de uma grife estrangeira. Trata-se de uma tática comum empregada pela mídia, sob alegação de que é mais convincente transformar uma menina numa mulher do que "consertar" sinais do tempo ao usar uma imagem que realmente tem a idade que deveria representar. Seguindo essa mesma lógica é que os retoques digitais se tornaram tão comuns, sendo alvo de críticas hoje em dia (Dunn, 2010).

Naomi Wolf atenta para as consequências dessas posturas, ressaltando que perdemos a noção de como uma mulher de verdade se parece. Em o "Mito da beleza" (1992) ela associa as obrigações com aparência a uma noção naturalizada de busca pela juventude. Durante muito tempo a beleza esteve associada a uma atribuição divina, sendo entendida como um dom que algumas pessoas recebiam e outras não. Com o tempo esse conceito foi modificado, amparado pela indústria de cosméticos que propagou a ideia de que a beleza está ao alcance de todas, basta querer (Sant'anna, 2004).

Entretanto, a contemporaneidade traz consigo algumas contradições, dentre elas a ênfase nos hábitos alimentares saudáveis e na atividade física associada à qualidade de vida de um lado, e de outro, o incentivo, através do capitalismo e da urbanização, do consumo de alimentos rápidos e calóricos (fast food), estimulando o aumento dos índices de obesidade e outros problemas de saúde. A mulher contemporânea encontra-se mais vulnerável aos ideais de beleza criados culturalmente do que em outros momentos na história, pressionada por representações sociais de punições (críticas, desprezo, deboche) e gratificações (dinheiro, poder, admiração, reconhecimento). Os ganhos secundários podem levar a renuncia ao contato interno e à perda da conexão com seu corpo real (Boris \& Cesídio, 2007; Carreteiro, 2005). 


\section{Corpos Performativos}

Se por um lado, o padrão corporal da moda induz à hegemonia do magro e ao aprisionamento do indivíduo aos seus ditames, por outro, podemos pensar o corpo e suas representações de uma maneira completamente atípica. A teoria queer, como uma crítica sem sujeito (subjectless), foca em um amplo campo de normalização como lócus de violência social, para as estruturas sociais hegemônicas que criam sujeitos como normais e naturais por meio da produção de outros perversos ou patológicos (Miskolci, 2007). Nessa teoria, entende-se que os corpos não estão presos a uma única possibilidade de existência e que vivem em constante mutação e materialização.

O conceito de performatividade é empregado por Butler (1993) para explicar como o gênero se manifesta nos corpos e como através desse mesmo conceito, se tornam sujeitos. No pós-estruturalismo, escola antipositivista e antidogmática, o sujeito é sempre encarado como provisório, circunstancial e cindido, onde a desconstrução do que está posto é a principal premissa (Miskolci, 2009).

Por performatividade dos corpos entende-se a maneira como as pessoas subvertem ou não a ordem heterossexista imposta, e vivenciam gênero; gênero, não como uma escolha, nem posterior ao sexo biológico, mas como resultado de uma reiteração de normas. Normas anteriores a quem as vivencia e que, pela repetição, materializam aquilo que nomeiam (Miskolci \& Pelucio, 2007). Ou seja, gênero não constitui uma identidade rígida, mas uma constante performance, uma vez que não encontra fundamento em nenhuma matriz original, apesar de o modelo social vigente ser baseado na matriz binária: masculino e feminino.

Butler (2008) usa o exemplo das drag queens, que se travestem e se fantasiam com roupas extravagantes no intuito de criar uma personagem, para falar de desconstrução da matriz binária. No entendimento da autora, elas representam uma paródia subversiva do masculino e feminino imposto; "ao imitar o gênero, o drag revela implicitamente a estrutura imitativa do próprio gênero - assim como sua contingência" (Butler, 2008, p.196). Numa analogia brasileira, Miskolci e Pelucio (2007) se apropriaram do conceito de performatividade para analisar o universo das travestis, entendendo a construção desses corpos também como paródia que subverte.

Surgida a partir dos estudos culturais, a teoria queer abrange inclusive obras artísticas e midiáticas, priorizando a análise desconstrutivista de produtos culturais como estratégia para sublinhar a centralidade da sexualidade na vida social contemporânea (Miskolci, 2007). Seu enfoque coloca em xeque as coerências e estabilidades que, no modelo construtivista da teoria social, fornecem um quadro compreensível e padronizado da sexualidade, questionando os processos sociais normalizadores que criam classificações, às quais, por sua vez, geram a ilusão de sujeitos estáveis, identidades sociais e comportamentos coerentes e regulares. Louro (2008) também contribui acerca desta teoria, destacando a importância das construções de gênero e sexualidade através da aprendizagem diária sobre tais conceitos, seja de forma explícita ou dissimulada, através da mídia - com nossa adequação às câmeras e o bombardeio de informações em novelas, comerciais, além da sedução que shoppings centers promovem em nossa constituição enquanto ser - ou de processos educativos mais sutis, com o auxílio dos valores familiares e de instituições tais como a escola e a igreja.

No universo da moda a subversão da matriz binária também pode ser pensada. A magreza evidente nos corpos das modelos é tamanha que os associa às formas retas masculinas. Por outro lado, as roupas, o gestual e a postura das modelos em questão remetem a um imaginário culturalmente associado ao feminino, pautado na sedução e cuidados com a aparência; uma associação ao feminino que talvez garanta a esses corpos a inteligibilidade necessária para que eles existam e sejam reconhecidos como possíveis. Inteligibilidade que, conforme Butler (2006), é produto do reconhecimento do acordo com as normas sociais vigentes. Em oposição aos corpos inteligíveis, estariam os corpos abjetos, possíveis enquanto materialidade, mas que não encontram espaço para serem compreendidos dentro da norma vigente. A moda está repleta de corpos abjetos, justamente por impor um padrão tão rígido, centrado no magro.

Mais recentemente, tentativas de trazer ao conhecimento e à inteligibilidade formas corporais que saem da norma foram propostas, porém dentro do que o filósofo Giorgio Agamben (2004) chamaria de exclusão pela inclusão, quando algo fora da norma é proposto de maneira a atestála; são exceções que existem apenas para manter a regra universalizante. São eventos ocasionais e que acabam ganhando destaque mais pela polêmica momentânea que provocam do que como perspectivas sérias de mudança. Como exemplo, temos as modelos plus-sized ${ }^{l}$ presentes nas revistas Glamour, nos Estados Unidos, e Brigitte, na Alemanha; a edição Black da Vogue Italia, composta apenas de modelos negras, o desfile de Walter Rodrigues no Fashion Rio, com elenco $100 \%$ negro, e o anúncio da grife francesa Givenchy, onde a transexual Lea-T é a modelo principal ${ }^{2}$.

\footnotetext{
1 "Plus-sized" se refere às modelos de formas mais amplas, no Brasil por vezes chamadas de "modelos com curvas" que vestem tamanhos maiores que 42

2 Site da Revista Veja. Transsexual brasileiro filho do ex-jogador Toninho Cerezo é estrela de campanha da grife Givenchy na Europa. Veja, São Paulo, 2010. Disponível em: < http://veja.abril.com.br/noticia/ celebridades/travesti-brasileiro-filho-de-toninho-cerezo-e-estrela-decampanha-da-givenchy>. Acesso em: 06 dez. 2010.
} 
O próprio movimento da "beleza real" foi criado por uma empresa de cosméticos como estratégia para vender cremes firmadores da pele, criando uma perspectiva de realidade livre de imperfeições.

\section{Considerações Finais}

É possível que a magreza presente na moda seja mesmo fruto de uma tentativa de desconstrução de gênero, mas atravessada por um contexto cultural em que a matriz binária e heterossexista ainda confere às mulheres um lugar secundário. $\mathrm{O}$ perfil propagado pelos profissionais da moda é o de uma mulher magra, alta e sem grandes concentrações de gordura, propondo um ideal andrógino, um corpo com ossos evidentes, desprovido de curvas, similar a um cabide. Bordo (1985, citado por Bordo, 1997) afirma que esse ideal andrógino está diretamente associado aos transtornos alimentares como a anorexia; explorado como uma possibilidade, expõe sua contradição interna, transformando-se num conflito que dilacera o sujeito em dois, numa batalha entre os aspectos masculinos e femininos do ser. O corpo esquelético comporta a ambiguidade do masculino e do feminino, a ponto de ser pensado como desconstrução da norma, apesar de aplicar-se com muito mais efeito às mulheres e estar diretamente ligado a problemas de saúde como a anorexia (Ida \& Silva, 2007).

Naomi Wolf (1992) entende que as sanções impostas ao próprio corpo são o último resquício de uma sociedade patriarcal que subjuga as mulheres ao segundo lugar, à condição de inferior e desprovida de poder. Numa associação com Foucault (2007), que estudou a relação entre o poder, o saber e o corpo na sociedade moderna, esse corpo magro e exaustivamente "trabalhado" precisa ser controlado a fim de ser domesticado. Por outro lado, as tecnologias de aprimoramento do corpo nos dizem que é possível obter qualquer tipo de corpo que se queira e que a magreza seria um reflexo dessas novas possibilidades, supostamente ao alcance de todos. Há quem se tatue, há quem se sujeite a cirurgias plásticas para modificar o que não está do seu agrado, e quem faça dieta para reduzir medidas. Esse raciocínio só seria possível num contexto em que o corpo não fosse percebido como um processador das modificações, como sugere o pensamento hegemônico, e que não existisse um padrão dominante oferecido como ideal.

A crítica de dança Helena Katz (2008, p.69) entende que o corpo "nunca existe em si mesmo, nem quando está nu". Para ela o corpo é um estado provisório, uma compilação de informações que se vincula aos acordos estabelecidos com o ambiente onde vive. Katz propõe o corpo-mídia, que rejeita a noção de corpo recipiente e veículo para informações, sendo esse não mais a base para transformações, mas parte integrante dela. Dessa forma, o corpo "estado transitório dos acordos feitos com o ambiente por onde circula, é sempre singular e único" (Katz, 2008, p.73).

Talvez o grande questionamento seja a maneira como essa busca pelo único e pela singularidade é apresentada pela mídia, tendo a moda como principal propagadora. Conforme vimos ao longo do texto, as motivações para intervenções estéticas podem ser diversas, mas o objetivo de colocar-se numa situação de empoderamento através do controle do próprio corpo é o mesmo. A teoria dos corpos dóceis de Foucault está presente em cada pessoa que tenta modificar sua aparência em busca do valor mais em voga na sociedade contemporânea - a felicidade -, seja pela submissão, seja pela subversão da ordem vigente.

\section{Referências}

Agamben, G. (2004). Homo sacer: o poder soberano e a vida nua. Belo Horizonte: UFMG.

Bordo, S. (1997). O corpo e a reprodução da feminidade: uma apropriação feminista de Foucault. In: A. M. Jaggar, Gênero, corpo, conhecimento. Rio de Janeiro: Rosa dos Tempos.

Bordo, S. (2003). Never just pictures. In A. Jones (Org.), The feminism and visual culture reader. London: Routledge.

Boris, G.D.J.B. \& Cesídio, M.H. (2007). Mulher, corpo e subjetividade: uma análise desde o patriarcado à contemporaneidade. Revista Mal-estar e Subjetividade, 7(2), 451-478.

Borowski, C. (2008). "Mulheres Frutas" dão seqüência ao reinado das bundas no Brasil. Veja, São Paulo. Disponível em: <http://www.abril.com.br/noticia/ diversao/no_292373.shtml>. Acesso em: 22 dez. 2010.

Butler, J. (1993). Bodies that matter: On the discursive limits of sex. London: Routledge.

Butler, J. (2006). Deshacer el género. Barcelona: Paidós.

Butler, J. (2008). Problemas de gênero: Feminismo e subversão da identidade. Rio de Janeiro: Civilização Brasileira.

Castilho, K. (2004). Do corpo presente à ausência do corpo: Moda e marketing. 2004. 243f. Tese de Doutorado em Comunicação e Semiótica, Pontifícia Universidade Católica de São Paulo, São Paulo.

Carreteiro, T. A. (2005). Corpo e contemporaneidade. Psicologia em Revista, 11(17), 62-76.

Costello, B. (2009). Kate Moss: The waif that roared. 
Women's Wear Daily, Londres. Disponível em: $<$ http://www.wwd.com/beauty-industry-news/ beauty-features/kate-moss-the-waif-that-roared2367932?full=true $>$. Acesso em: 20 dez. 2010.

Del Priore, M. (2000). Corpo a corpo com a mulher: Pequenas histórias do corpo feminino no Brasil. São Paulo: Senac.

Dunn, C. (2010). Mulheres reais tomam conta de revista e chamam atenção para onda anti-Photoshop. Zero Hora, Porto Alegre. Donna ZH. Disponível em: $\quad<$ http://www.clicrbs.com.br/especial/rs/ donna/19,207,3035543,Mulheres-reais-tomamconta-de-revista-e-chamam-atencao-para-onda-antiPhotoshop.html>. Acesso em: 04 jan. 2010.

Farias, R. C. P. (2009). Conjugalidade e profissão de modelo: projetos conflitantes ou complementares? Cadernos Pagu, Campinas, 33, 167-197.

Fashion Forward (2010). Paulo Borges e Anna Wintour discutem a saúde das modelos. Disponível em: <http:// ffw.com.br/noticias/cfda-paulo-borges-anna-wintour>. Acesso em: 15 nov. 2010.

Foucault, M. (2007). Vigiar e punir: História da violência nas prisões. Petrópolis, RJ: Vozes.

Gaier, R. V.; Grudgings, S. (2010). The chubby girl from Ipanema? Brazil puts on weight. Disponível em: <http://www.reuters.com/article/ idUSTRE67Q3UK20100827>. Acesso em: $22 \mathrm{dez}$. 2010

Goldenberg, M. \& Ramos, M.S. (2002). A civilização das formas: O corpo como valor. In: M. Goldenberg (Org.), $\mathrm{Nu}$ e vestido: Dez antropólogos revelam a cultura do corpo carioca. Rio de Janeiro: Record.

Halfen, E., \& Damasceno, S. E. (2010). Cinedebate transtorno alimentar: Anorexia. Palestra proferida no Centro de Psicologia Cognitiva em 16 de novembro de 2010.

IBGE - Instituto Brasileiro de Geografia e Estatística. (2008). Disponível em: <http:// www.saladeimprensa. ibge.gov.br>. Acesso em: 6 dez. 2010.

Ida, S.W., \& Silva. R.N. (2007). Transtornos alimentares: Uma perspectiva social. Revista Mal-estar e Subjetividade, 7(2), 417-432.

Katz, H. (2008). Por uma teoria crítica do corpo. In: A. C. Oliveira; K. Castilho (Org.), Corpo e moda: Por uma compreensão do contemporâneo. Barueri: Estação das Letras.

Louro, G.L.(2008). Gênero e sexualidade: Pedagogias contemporâneas. Pro-Posições, 19(2), 17-23.

Martins, V.L. (2010). Valores estéticos e estigmas sociais ligados ao culto à beleza. Revista Científica Intraciência,2(1), 27-105.

Miskolci, R. (2007). A Teoria Queer e a questão das diferenças: Por uma analítica da normalização. $16^{\circ}$ Congresso de Leitura do Brasil. Disponível em: http:// alb.com.br/arquivo-morto/edicoes anteriores/anais16/ prog_pdf/prog03 01.pdf.

Miskolci, R. (2009). A Teoria Queer e a Sociologia: O desafio de uma analítica da normalização. Sociologias, Porto Alegre, 11(21), 150-182.

Miskolci, R., \& Pelúcio, L. (2007). Fora do Sujeito e Fora do Lugar: reflexões sobre performatividade a partir de uma etnografia entre travestis. In Revista Gênero, Niterói, 7(2), 257-267.

Niemeyer, F., \& Kruse, M. H. L. (2008). Constituindo sujeitos anoréxicos: discursos da revista capricho. Texto \& Contexto Enfermagem, Florianópolis, 3(17), 457-465.

Odell, A. (2010). Fifteen-Year-Old Lindsey Wixson's Miu Miu Ads Debut. The Cut, New York. Disponível em: $<$ http://nymag.com/daily/fashion/2010/02/15-yearold_lindsey_wixsons_mi.html $>$. Acesso em: $22 \mathrm{dez}$. 2010 .

Queiroz, E.F. (2008). O inconsciente é psicossomático. Revista Mal-Estar e Subjetividades, 8(4), 911-924.

Revista Veja. (2009). SPFW terá cota para negros. Veja, São Paulo. Disponível em: <http://veja.abril.com. $\mathrm{br} /$ noticia/variedade/spfw-tera-cota-negros-471753. shtm>. Acesso em: 22 dez. 2010.

Rousso, F. (2000). A beleza através da história. In C. Jazdzewski, F. Rousso, F. Vormese, F. Mohrt, M-P. Lannelongue, \& N. Chahine, Beleza do século (pp. $25-$ 77). São Paulo: Cosac \& Naify.

Sant'anna, D.B. (2004). Cultos e enigmas do corpo na história. In: M. N. Strey, \& S. T. L. Cabeda, Corpos e subjetividades em exercício interdisciplinar. Porto Alegre: EDIPUCRS.

São Paulo Fashion Week (2007). Coma bem e sem culpa: Um guia de alimentação saudável para modelos. Disponível em: <http://ffw.com.br/noticias/files/ cartilha-dieta-modelos.pdf $>$. Acesso em: 15 nov. 2010.

Schwengber, M.S.V. (2009). Corpo grávido: Um corpo inquieto por conta de sua saúde e de sua beleza. In Seminário Corpo, Gênero E Sexualidade, 4. Anais, Rio Grande: FURG. 
Severiano, M.F.V. Rêgo, M.O. E.V.R. \& Montefusco (2010). O corpo idealizado de consumo: paradoxos da hipermodernidade. Revista Mal-estar e Subjetividade, 10(1), 137-165.

Stenzel, L. M. (2004). Servir (vir a ser): o imperativo do corpo magro na contemporaneidade. In M. N. Strey, \& S. T. L. Cabeda. Corpos e subjetividades em exercício interdisciplinar (pp.179-194). Porto Alegre: EDIPUCRS.

Strey, M. N. (2004). A "criação" do corpo feminino ideal. In M. N. Strey, \& S. T. L. Cabeda. Corpos e subjetividades em exercício interdisciplinar. Porto Alegre: EDIPUCRS.

Terra [Site Provedor de Internet]. (2006). Modelo morre de anorexia aos 21 anos e com $40 \mathrm{~kg}$. Retirado de: $\underline{\mathrm{http}: / /}$ noticias.terra.com.br/brasil/interna/0,,OI1248775EI306,00.html, em: 01 out. 2009.

Vieira, C.A.L. (2008). Anorexia: uma tentativa de separação entre o Sujeito e o Outro. Revista Mal-estar e Subjetividade, 7(3), 645-660.

Vilhena, J., \& Novaes, J.V. (2008). Comendo, comendo e não se satisfazendo: apenas uma questão cirúrgica? Obesidade mórbida e o culto ao corpo na sociedade contemporânea. Revista Mal-estar e Subjetividade, 7(2), 379-406.

Wolf, N. (1992). O mito da beleza: como as imagens de beleza são usadas contra as mulheres. Rio de Janeiro: Rocco.

\section{Endereço para Correspondência:}

Fernanda Lyrio Heinzelmann

Endereço: Rua Brigadeiro Galvão, n 150, Ap. 124 - Barra

Funda. São Paulo/SP - CEP.: 01151-000

Email: fergolina@gmail.com

\section{Endereço para Correspondência:}

Patrícia Fasolo Romani

Endereço: Av. Nilópolis, no 245, Ap. 302 - Bairro

Petrópolis. Porto Alegre/RS - CEP.: 90460050

Email: pattyfaro@hotmail.com

\section{Endereço para Correspondência:}

Adriana Lessa

Endereço: Rua Fernando Borba, $n^{\circ} 60$ - Bairro Ipanema.

Porto Alegre/RS - Cep : 91751-160

Email: adriilessa@gmail.com

\section{Endereço para Correspondência:}

Marlene Neves Strey

Endereço: Rua Garibaldi, no 1244, Ap. 501 - Bairro Bom Fim. Porto Alegre - RS - CEP: 90035052

Email: streymn@pucrs.br

\section{Endereço para Correspondência:}

Marília Saldanha

Rua Demétrio Ribeiro, no 1017, Ap. 605 - Bairro Centro

Histórico. Porto Alegre/RS - CEP.: 90010311

E-mail: mariliasaldanha@yahoo.com.br 